\title{
Crazy Rich Asians: A tale of immigration, globalization and consumption in East Asia
}

\author{
Giana M. Eckhardt \\ Royal Holloway University of London \\ Finola Kerrigan \\ University of Birmingham, UK
}

Follow this and additional works at: https://digitalcommons.uri.edu/mgdr

Part of the Anthropology Commons, Economics Commons, Film and Media Studies Commons, Marketing Commons, Other Business Commons, and the Sociology Commons

\section{Recommended Citation}

Eckhardt, Giana M. and Kerrigan, Finola (2019) "Crazy Rich Asians: A tale of immigration, globalization and consumption in East Asia," Markets, Globalization \& Development Review. Vol. 4: No. 3, Article 5. DOI: 10.23860/MGDR-2019-04-03-05 Available at: https://digitalcommons.uri.edu/mgdr/vol4/iss3/5

This Media Review is brought to you for free and open access by DigitalCommons@URI. It has been accepted for inclusion in Markets, Globalization \& Development Review by an authorized editor of DigitalCommons@URI. For more information, please contact digitalcommons@etal.uri.edu. 
Crazy Rich Asians: A tale of immigration, globalization and consumption in East Asia

\section{Markets, Globalization \& Development Review}
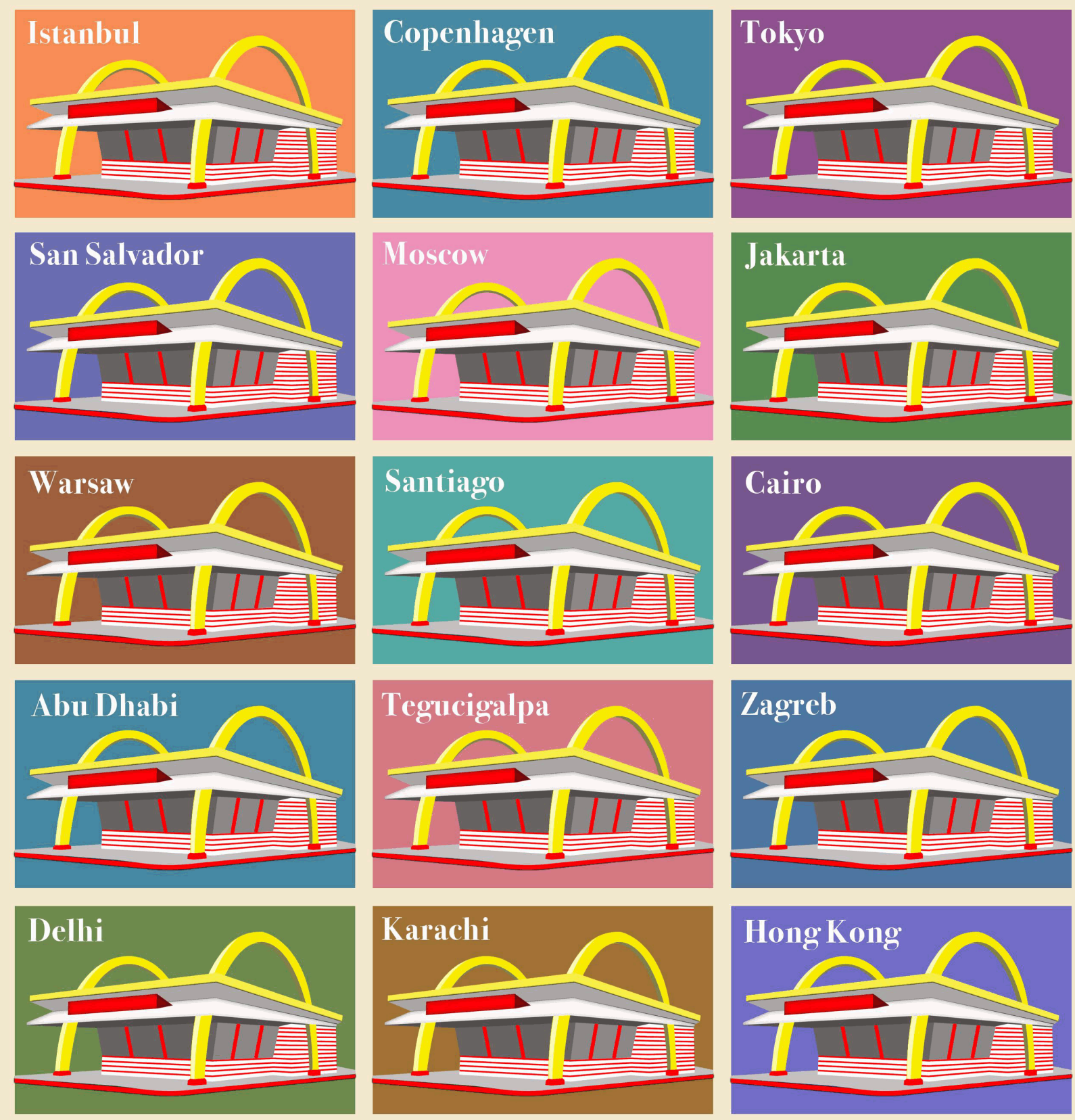

This media review is available in Markets, Globalization \& Development Review: https://digitalcommons.uri.edu/ $\mathrm{mgdr} / \mathrm{vol} 4 / \mathrm{iss} 3 / 5$ 


\section{Crazy Rich Asians: A Tale of Immigration, Globalization and Consumption in East Asia}

\section{Introduction}

In 2018, Crazy Rich Asians (CRA) burst onto our screens, taking over $\$ 26$ million for its opening weekend in the US (Box Office Mojo 2019). The team behind the film had gambled correctly in turning down a Netflix deal that would have skipped a theatrical release, to take a less lucrative offer from Warner Brothers (Sun and Ford 2018). In the year since its release, the film has made over $\$ 238$ million worldwide (Box Office Mojo 2019), and a sequel is already in the works. The film made an outsized cultural impact due to it being the first mainstream, global romantic comedy with an all ethnically Chinese cast. CRA is set primarily in Singapore and focuses on the story of a Chinese American college professor, Rachel, who travels to Singapore to meet her boyfriend Nick's family and to attend the wedding of Nick's best friend. On arriving in Singapore, she discovers that Nick's family are one of the richest and most well known in Singapore and among the wider, pan-Asian Chinese diaspora. His family does not accept her, as she is not from a prominent family, and thinks that her focus on attaining her own goals - getting a Ph.D. and becoming an academic at New York University - represents the individualism of the US, rather than the sacrifice of giving up your dreams to support your family. Rachel eventually wins Nick's family - and in particular, his mother - over, and the film ends with her engagement to Nick with the blessing of his family. Our review examines the film through setting CRA within the context of East Asian consumer culture. By examining the storyline and the film's reception, in the West and in Asia, we offer insight into contemporary globalization debates.

The film showcases Singapore as a glitzy, modern global city, and several well-known local actors are in the cast, along with a host of ethnically Chinese actors from around the world. Based on novels by Kevin Kwan, CRA is set within the elite Chinese Singaporean community with whom Kwan went to school. Critics of the film have focused on the lack of representation in terms of the diversity of Singapore, with its many ethnicities (Han 2018). Han's (2018) critique argues that - while Chinese Americans may welcome their prominent visibility in comparison to typical Hollywood stories - despite the Singaporean setting, CRA is a Hollywood production that whitewashes Asian stories and engages in stereotyping.

This may explain why, despite the storyline focusing on the highly networked elite Chinese diaspora, the film took in only $\$ 1.6$ million in China. A variety of explanations have been offered for this 
poor performance in China. These range from the film's late release in China, to the fact that Nick and his mother, both Malaysian Chinese actors whose first language is Cantonese rather than Mandarin, spoke Mandarin with an accent, to lackluster marketing in China (Yu 2018). The film's sequel, entitled 'China Rich Girlfriend', is set to take place in Shanghai, and is designed to attract a larger Chinese audience. However, tension is apparent in the development of the sequel, with co-writer Adele Lim stepping away from the project, saying that she did not want to be involved just to add 'soy sauce' or 'cultural specificity' to the script. Lim objected to the lack of pay parity and position between her and co-writer Peter Chiarelli (Liu 2019).

The film's overwhelming success came from English speaking regions, with the US market comprising $73.2 \%$ at $\$ 174.5$ million, Australia bringing in just over $\$ 17$ million, followed by the UK at $\$ 7.6$ million (The Numbers 2018). Heralded as the first Hollywood film to feature an almost entirely Asian cast since the 'Joy Luck Club' in 1993, many of the main cast members were Asian American or British Asian, therefore providing a connection for audiences from these territories to the film. Apart from financial success, CRA also attracted critical acclaim, with Golden Globe nominations for Best Motion Picture and Best Actress for Comedy or Musical, and a Screen Actors Guild Award for outstanding cast.

Setting aside concerns regarding representation of Singapore expressed in articles such as Han's (2018), CRA earned \$5.3 million in Singapore, and has been embraced by the tourism sector there. Screen tourism is well established (e.g. Volo and Irimiás 2016) and this is certainly a central part of the current Singapore Tourism Board's approach to promoting the island $(\mathrm{TIH} 2018)$.

\section{Immigration and Globalization in CRA}

The film begins in 1995, in a scene where as a child, Nick arrives at a high end London hotel with his family. The manager insists they do not have a reservation and will not let them stay. "May I suggest you explore Chinatown," the manager replies to their insistence that they have a reservation. Nick's mother calls the owner of the hotel who comes immediately and tells the manager to give them the most luxurious suite, as they are the next owners of the hotel, much to the manager's chagrin. This contrasts with the acceptance of East Asians across the globe in 2018 as portrayed in the rest of the film, recognizing the high levels of wealth that elite East Asians have, and welcoming their presence in elite global spaces. This highlights how the nature of globalization has changed in just twenty years, with those previously from the periphery - the Chinese diaspora - now fitting comfortably in the 'center' (the West) (Said 1978). This echoes the 
depictions of East Asians that Cayla and Eckhardt (2008) discuss which have broad appeal across the region - wealthy, modern and at home in global spaces such as New York. In the 2018 of CRA, it is the elite Chinese talking down to other ethnicities, in a reversal of the 1995 scene depicted at the outset of the film.

The film also explores the complexities of how immigration is seen and how it has changed over the years. For example, Rachel's mother was a factory worker in China, and immigrated to the US to better herself and her daughter, becoming a successful real estate agent in New York, with an economics professor daughter teaching at New York University. The immigration undertaken by Nick's family, on the other hand, was of a different character. Although not stated in the film, most likely the family got out of mainland China at the time of the Revolution, to maintain their wealth, and migrated to other East Asian cities that offered opportunities to grow their wealth, such as Singapore, Hong Kong and Taipei. Later, the younger generation immigrated to London and New York for education opportunities. This form of immigration - moving to global wealth and education centers to become a part of the global elite - is valorized in the film, in comparison to the 'old' model of non-elites immigrating for work and opportunities to improve their socioeconomic status, which is derided (in terms of the scorn heaped on such lowly immigrants, by Nick's mother and grandmother). At its core, the American Dream is being portrayed as a passé model of immigration - that is not revered anymore and is in fact looked down upon and sneered at. This critique is radical for a mainstream romantic comedy, and perhaps augers a new era of global, mainstream storytelling which is not so rooted in American values and mores.

We can also examine the history of Singapore as a colonial subject as depicted in the film. Sir Thomas Stamford Raffles of the East India Company took ownership of the port of Singapore from Malaysia in 1819, before Singapore, Malacca and Penang became British colonies. This established the island as a strategic part of the British Empire until it was occupied by the Japanese during World War 2. We can see trappings of British colonial life in the film, from the Christian prayer group to the turbaned Sikhs guarding the gates of Nick's family mansion. This use of English colonial tropes by the Singaporean Chinese elite is again a reversal of the opening scene of the film, and emphasizes the importance of changing patterns of immigration, which have and continue to impact Singaporean/Chinese identity.

\section{Critique of American Ideals and Values}

As mentioned above, CRA appealed most to audiences in the US, and the US focus of the film is evident throughout. Rachel, although coming 
from a Chinese background, is a New Yorker. The opening scenes establish her life as a middle class professional who has fulfilled the American dream. As the child of a Chinese migrant who came to the US with nothing, she has gained a Ph.D. in Economics from an Ivy League school (Columbia) and works at an elite private university (NYU). This fulfills the cultural trope so common in US films - that hard work and 'earned upward mobility' is rewarded. Through the Chinese Singaporean elite, film, however, the film offers a critique of this American dream. While in an immigrant family, achieving academic and economic success such as Rachel's can be seen as the ultimate goal, and humble roots can be worn like a badge of honor, this holds little currency for the Chinese Singaporean elite. Rather than who you have become, the focus in the film is on history and lineage. The recurring question of 'which Chu' family Rachel was from - portrayed humorously in a scene by the comedic actor Ronnie Chieng - points to the value of heritage within this social circle. Rachel was not seen as possessing the social or cultural capital required to make it in Singaporean high society. Despite Rachel referring to herself as "so Chinese I'm an econ professor with lactose intolerance," Rachel's credentials as ethnically (elite) Chinese are doubted throughout. Not growing up in Asia is seen as lacking ethnic authenticity. Nick's mother says that "when children are away from home too long they forget who they are," and Rachel's mother was referred to as a "low class immigrant nobody."

Yet despite Rachel representing the ultimate American Dream success story, she is widely critiqued throughout the film, and as such, the American Dream itself is critiqued. While Nick's family and their social circle lived, studied and worked on multiple continents, Rachel (despite her profession and standing in the US) is depicted as parochial. When Nick suggested a trip east, Rachel first thought he meant to New York's Greenwich Village, when he said to think a little further east, she came back with "you mean Queens?" For her, the wealthy Chinese diaspora and their globe-trotting lifestyle is unimaginable. While in many Hollywood films, the US and American lifestyle are depicted as aspirational, this is not the case in CRA. While Changi airport is lauded for its butterfly garden and movie theatre (and the film does not even mention the rooftop swimming pool), JFK airport is described as offering "salmonella and despair." The depiction of the US as the land of abundance is also challenged with Rachel's college friend's father, Mr. Goh, encouraging his twin daughters to eat their chicken nuggets as "there's a lot of children starving in America," pointing to Rachel to illustrate. In CRA, the old tropes of the Americans being top dogs is flipped on its head and the disorientation that Rachel feels illustrates this. This overt critique of the American dream, and how inferior its results are compared to the Chinese diaspora wealth 
that has been accumulated all over East Asia, makes it even more remarkable that the movie had appeal to US and Anglo audiences, and not as much to Asian audiences. This is perhaps a harbinger that the narratives that are appreciated in global popular culture, even by Americans themselves, are beginning to turn away from being UScentric and towards narratives originating from other global hotspots. Is the US reign over popular culture and, in particular, Hollywoodized film culture, finally over?

\section{The Complexities of Consumption}

Over-the-top conspicuous consumption is depicted throughout the film, although there is a stark divide between old and new money. On the surface, the film is a celebration of excess. Flying first class, lavish homes, jewelry and clothing, and a disdain on the part of the oldmoney Chinese diaspora toward the new-money Chinese diaspora (whose trappings of wealth are gaudier). Indeed, this lauding of excessive wealth is one of the explanations offered as to why audiences in communist China did not relate to the film (Yu 2018). Yet, critiques of this culture of conspicuous consumption exist within the film. For example, Nick's cousin Astrid, who is a celebrity and ultra-rich, feels she must hide her spending on accoutrements such as shoes and jewelry from her husband, who used to be in the army and is now an entrepreneur; a 'commoner' as he refers to himself. It is made clear that, for others, having to be close to this constant conspicuous display of wealth, takes a toll. Indeed, this couple ultimately splits up, which serves as a warning sign to Rachel - should she, a 'commoner' also, enter into this world, with all its superficiality and power imbalances that come along with great wealth?

Another scene which harbors a critique of this lifestyle is when Rachel goes on a bachelorette weekend to an island with Nick's best friend's fiancée, Araminta. When all the women first arrive to the island, Araminta announces that the weekend will begin with a free shopping spree, and all the women rush to the free clothes in a frenzy, fighting over particular pieces, with the exception of Rachel. This scene purposefully leaves a bad taste in the viewer's mouth, as these characters have unlimited wealth yet will do anything to amass more possessions. Just in case the message was not communicated, the sound track to the scene is Sally Yeh's Cantonese version of Material Girl by Madonna, while one of the guests notes "no one likes free stuff more than rich people." As suggested by Eckhardt and Bardhi (2019), the contours of conspicuous consumption have shifted in contemporary modernity, and in this scene, they are almost inverted from the classic Veblenian take on conspicuous consumption. In other words, the characters in this scene of CRA should be elite enough to not have to engage in a conspicuous display, suggesting that the dynamics of a 
Veblenian analysis is complex and perhaps not as relevant in an East Asian setting (Hughes, Eckhardt, Kaigler-Walker and Gilbert 2015).

\section{Conclusion}

A major critique of the film has been that it does not depict Singaporean life or racial relations in all its complexity, and it should, given the majority of the action takes place in Singapore (Bahrawri 2018). This is undoubtedly true - ethnically Indian Singaporeans, for example, when they appear at all, are only depicted as service workers. The film, however, is not about Singaporean life in general, but rather focuses on the global Chinese elite diaspora experience. This is evident from the montage at the beginning depicting members of Nick's Chinese family living in Taipei, Shanghai, New York, Hong Kong and Singapore; through to the casting, which features the leading Chinese ethnicity actors from the US, the UK, Singapore and Malaysia. Yet if the film is read as a treatise on the elite Chinese diaspora experience rather than as a Singaporean film, it is still criticized as highlighting negative elements of Chinese society such as materialism (Yu 2018). We have suggested that while these analyses have merit, the film is more complex than these critiques would suggest, in particular in terms of the valorization of conspicuous consumption.

Another prominent criticism has been that the film is a representation of East-Asianness designed to appeal to a Western audience (Bahrawi 2018). Indeed, although the book was written by a Chinese Singaporean, the film is an American production and the director is Asian American. The lead author has previously argued that the criticism lobbied against the movie Black Panther - that it was shot with a Western gaze and for a Western audience - does not hold up upon further scrutiny (Eckhardt 2018). In the case of 'Crazy Rich Asians', however, this does ring true. Box office numbers support the view that this was a story most appreciated by non-Asian audiences. As a comparison point, we can look to a previous global box office hit from East Asia, Ang Lee's 'Crouching Tiger Hidden Dragon' in 2000 which was both a critical and box office success all over the world. Like Zhang Yimou's 'Hero' in 2003 and 'House of Flying Daggers' in 2004 which also gained international success, the film was very Chinese, in the sense that it pulled from Chinese myths and martial arts and was steeped in Chinese aesthetics. While these films found success with international audiences, for the East Asian diaspora living in Western countries, they did not reflect their stories, conflicts and identity. As shown by Cayla and Eckhardt (2008), what appeals to that audience is narratives and aesthetics reflective of global modernity. CRA is steeped in global modernity. On the one hand, the criticism of CRA being 'whitewashed' because a film is relatable to global audiences and uses universal stories rather than stories steeped in the locale of 
origin, is an Orientalist expectation in itself (Said 1978). On the other hand, the film did not appeal to Chinese audiences in the numbers it had hoped to, suggesting perhaps that the focus on the Chinese elite diaspora was not relatable to the average Chinese moviegoer.

In sum, what we can take away from CRA is that the film serves a variety of functions in different social, global and political contexts. How viewers engage with a film will be dependent on their own historical perspective, their identity and their understanding of others. Perhaps one of the most important outcomes of CRA's success is that it can pave the way for a variety of other film narratives that will embody East Asian values, mores and aesthetics, and present a vision of East Asian modernity to the rest of the world. For CRA, the success of the film is always portrayed in the media as 'surprising'; in the future, mainstream movies from East Asia and around the world doing well globally will hopefully be de rigueur. 


\section{References}

Bahrawri, Nazry (2018), "Crazy Rich Asians: The Return of Sham-East Asia?", Al Jazeera, September 2, (accessed September 14, 2019), [available at: http://bit.ly/CRA-AlJazeera1].

Box Office Mojo (2019), Crazy Rich Asians, (accessed September 14, 2019), [available at: http://bit.ly/CRA-Mojo1].

Cayla, Julien and Giana M. Eckhardt (2008), "Asian Brands and the Shaping of a Transnational Imagined Community", Journal of Consumer Research, 35 (2), pp. 216-30. https://doi.org/10.1086/587629

Eckhardt, Giana M. (2018), "Black Panther: Thrills, Post-Colonial Discourse and Blacktopia", Markets, Globalization and Development Review, 3 (2), Article 6. https://10.23860/MGDR2018-03-02-06

Eckhardt, Giana M. and Fleura Bardhi (2019), "New Dynamics of Status and Distinction", Marketing Theory, https://doi.org/10.1177/1470593119856650

Han, Kirsten (2018), "Crazy Rich Asians is a Win for Asian Americans. But It Gets Singapore Wrong", Vox, August 17, (accessed September 14, 2019), [available at: http://bit.ly/CRA-Vox1]. Liu, Jennifer (2019), "The 'Crazy Rich Asians' Sequel is Delayed Amid a Pay Dispute", CNBC, (accessed September 20, 2019), [available at: https://www.cnbc.com/2019/09/06/crazy-richasians-co-writer-adele-lim-quits-sequel-due-to-pay-gap.html].

Ucok Hughes, M., Giana Eckhardt, Karen Kaigler-Walker and Zelda Gilbert (2015), "The Discontinuous Evolution of Women's Fashion in China", Qualitative Market Research: An International Journal, 18 (4), pp. 391-408. https://doi.org/10.1108/QMR-072014-0061

The Numbers (2019), Crazy Rich Asians, (accessed September 14, 2019), [available at: http://bit.ly/CRA-Numbers1].

Said, Edward (1978), Orientalism. New York: Pantheon Books.

Sun, Rebecca and Rebecca Ford (2018), "The Stakes Are High for 'Crazy Rich Asians' - And That's the Point", The Hollywood Reporter, [available at: http://bit.ly/CRA-Hollywood1].

TIH (2018), "Discover Singapore through These Crazy Rich Experiences", Tourism Information and Services Hub, (accessed September 14, 2019), [available at: http://bit.ly/CRASingapore1].

Volo, Solo and Anna Irimiás (2016), "Film Tourism and Post-Release Marketing Initiatives: A Longitudinal Case Study", Journal of Travel \& Tourism Marketing, 33 (8), pp.1071-87. https://doi.org/10.1080/10548408.2015.1094000 
Yu, Katrina (2018), "Why Crazy Rich Asians was a Box Office Flop in China", Al Jazeera, December 13, (accessed September 14, 2019), [available at: http://bit.ly/CRA-AlJazeera2]. 